\title{
Erratum to: Recovery of Copper from Nickel Laterite Leach Waste by Chemical Reduction Using Sodium Dithionite
}

\author{
A. B. Botelho Junior, I. A. Anes, M. A. Carvalho, D. C. R. Espinosa
} and J. A. S. Tenório

\section{Erratum to:}

Chapter "Recovery of Copper from Nickel Laterite Leach Waste by Chemical Reduction Using Sodium Dithionite" in: Z. Sun et al. (eds.), Energy Technology 2018, The Minerals, Metals \& Materials Series, https://doi.org/10.1007/978-3-319-72362-4_38

In the original version of the book, the misspelt co-author name "M. A. Caralho" has been corrected as "M. A. Carvalho" in chapter "Recovery of Copper from Nickel Laterite Leach Waste by Chemical Reduction Using Sodium Dithionite", front matter (Table of Content) and Author Index. The erratum book has been updated with the change. 